\title{
Public perceptions of New Zealand freshwater and its management - reconciling the science and management implications
}

Ken F.D. Hughey

Geoff N. Kerr

Ross Cullen

Sheralee MacDonald

Lincoln University

2005 


\section{Outline}

- Outline of the biennial perceptions survey.

- New Zealanders' perceptions of freshwater using Pressure-State-Response model

- Trends in perceptions

- With demographic differences

- Comparisons between perceptions and the reported state of freshwater.

- Lessons and policy implications for freshwater management. 


\section{The biennial perceptions survey}

- A postal questionnaire based on the Pressure-State-Response model (PSR) - gathered information on perceptions of the environment and its management.

- 2,000 people aged 18 and over randomly selected from electoral roll - effective response rate of $43 \%$ achieved in 2004.

- Demographic variables include: region, ethnicity, recreational angler status, and employment sector.

- Regions: North = north of the Bombay Hills; Central = rest of the NI; Southern = South Island.

- Ethnicity: NZ European, Maori, and Other.

- Non-Anglers = 'never fished and don't want to'; Anglers = people who fish now, have fished, or intend to fish.

- Employment sectors: Resource based (farming, forestry and other primary sectors), and Other.

- Data analysed descriptively and, where applicable, the 2004 survey responses were compared with 2002 and 2000 surveys. 
Perceptions based on the NZwide freshwater context 


\section{Pressures: Most important environmental issue in NZ}

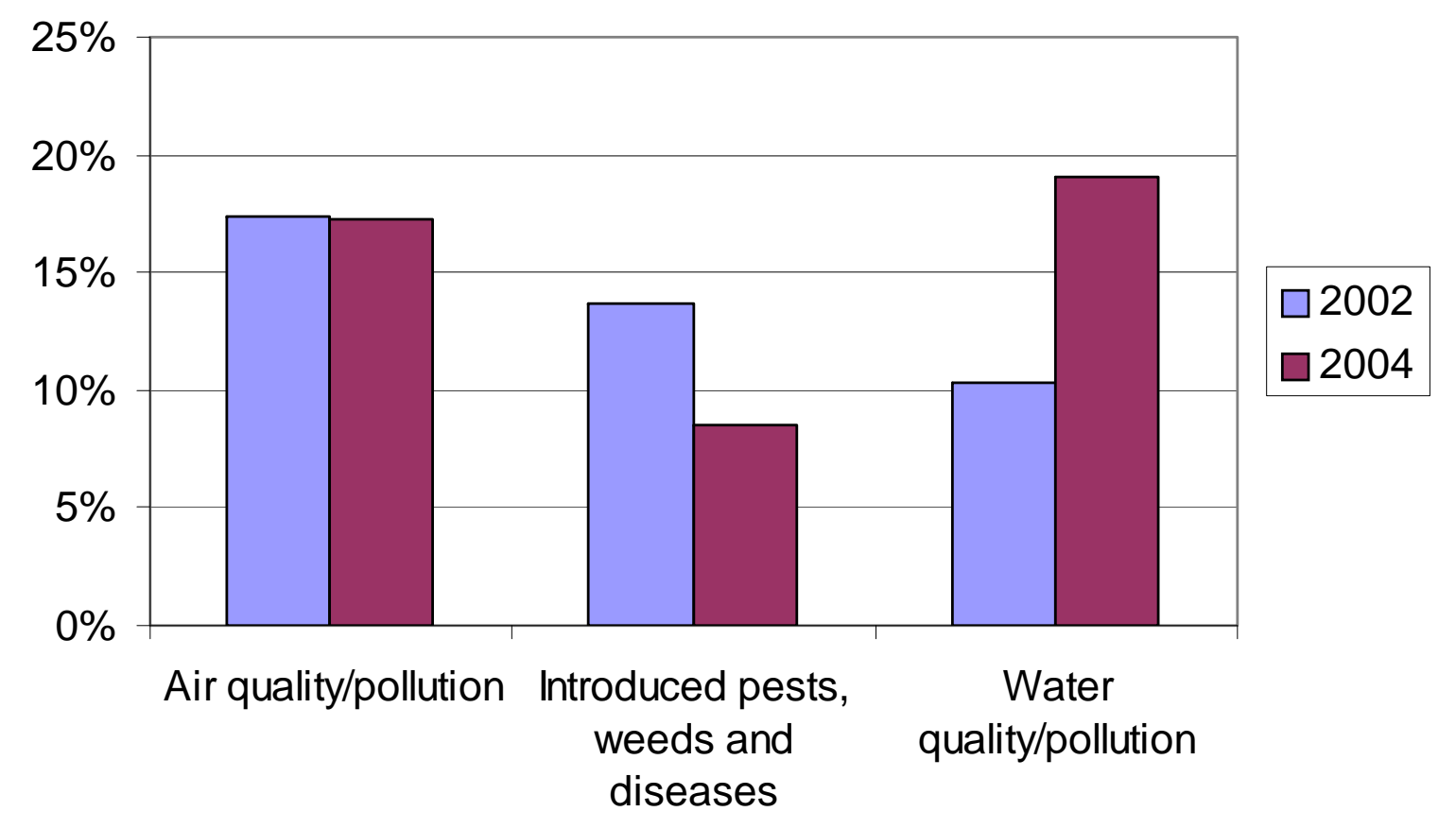

- A change from air in 2002 to water in 2004 (with regional differences) 


\section{Pressures:}

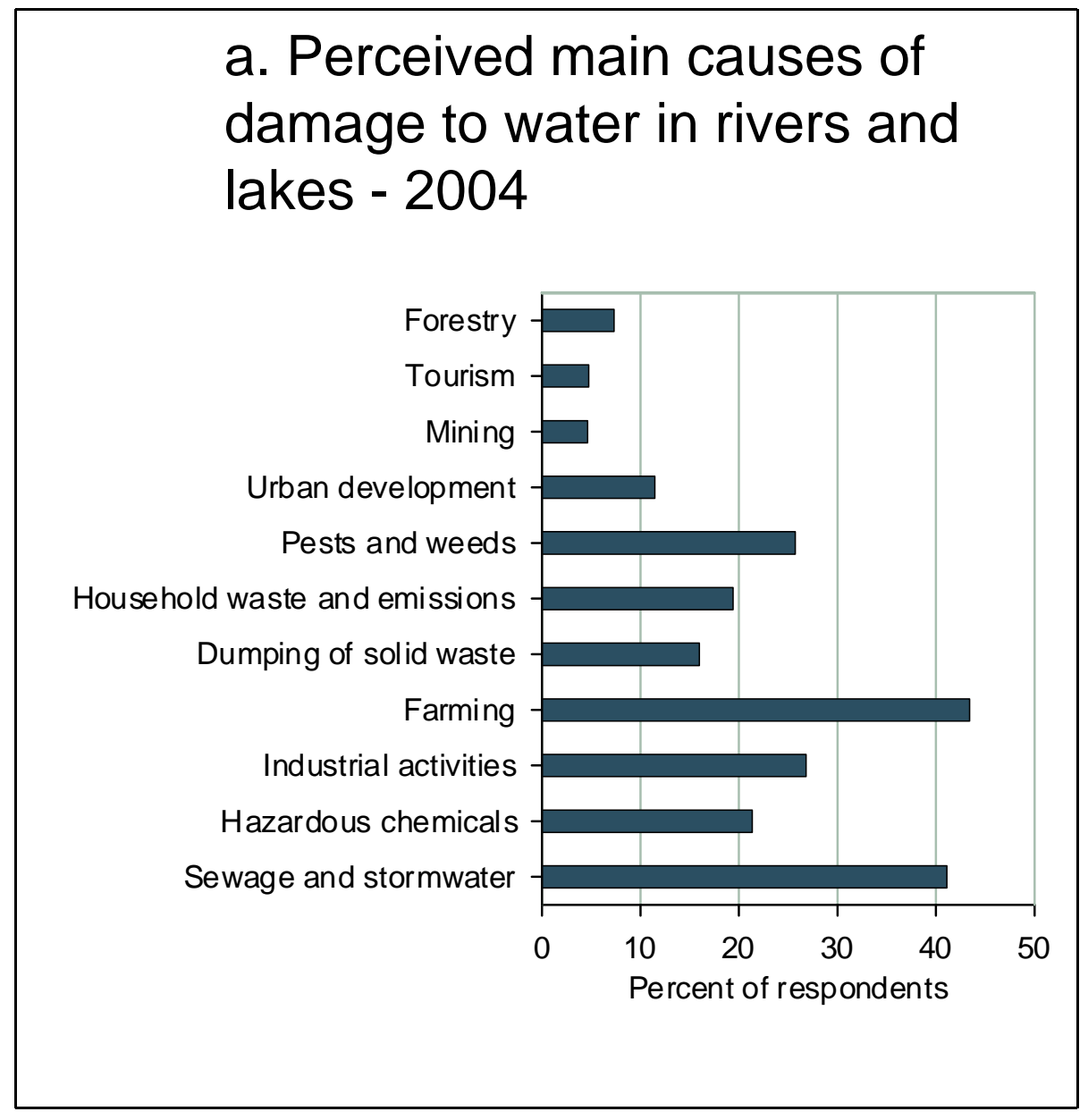

\section{b. Comparison of the perceived main}

causes of damage to freshwater

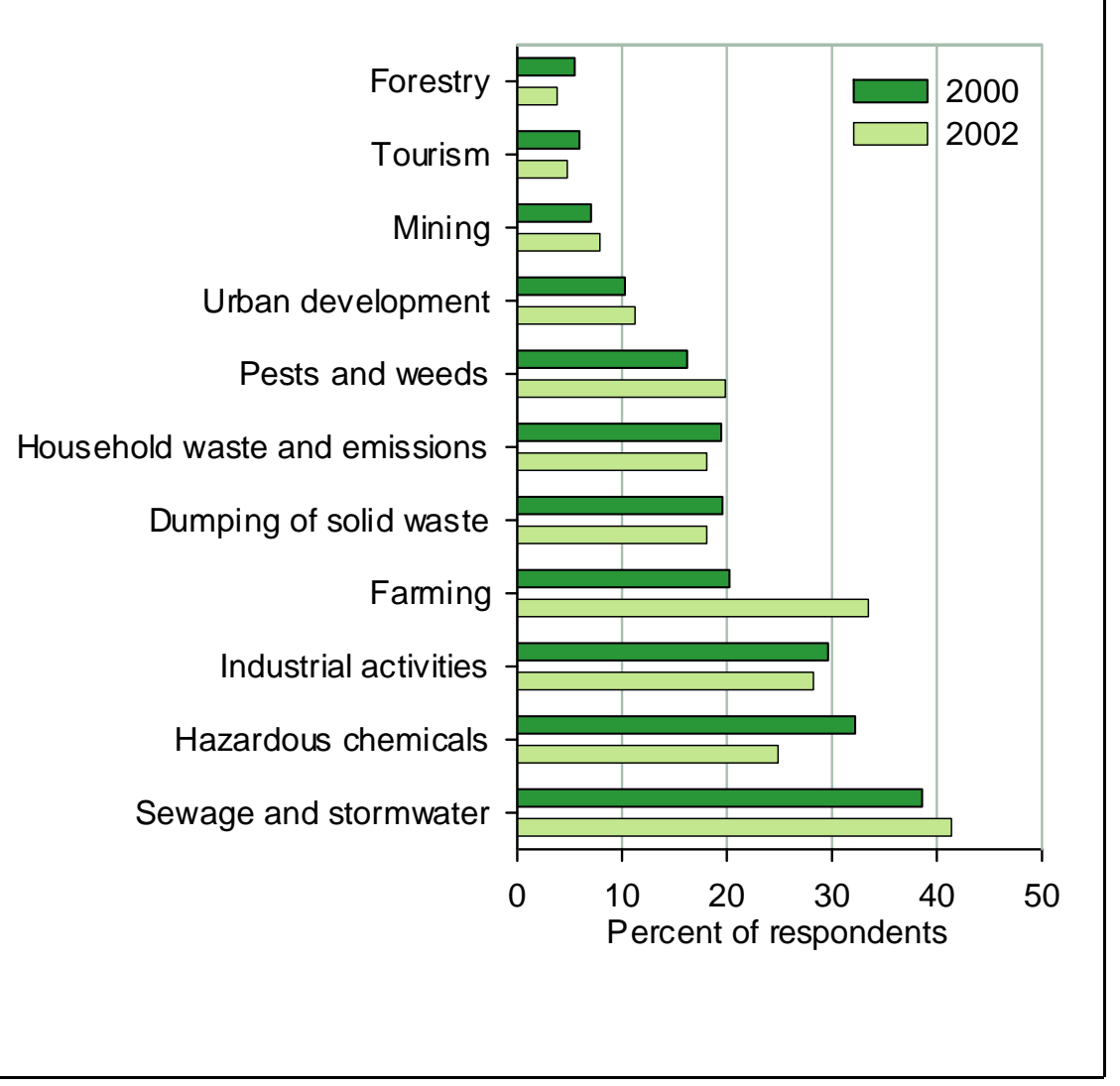




\section{Pressures: causes of damage to water in rivers and lakes (ethnic differences) (damage categories}

$<10 \%$ omitted)

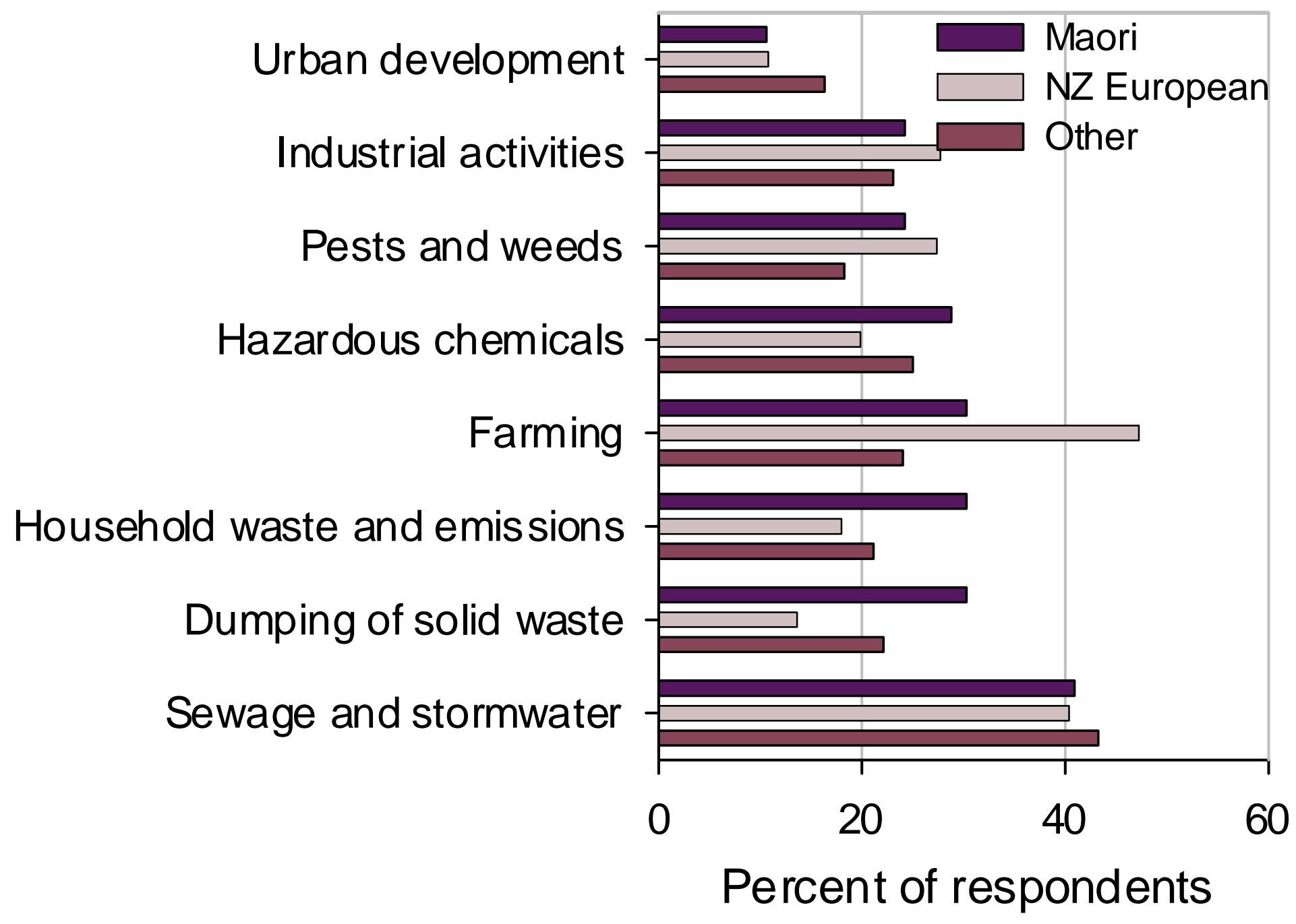




\section{State: Perceptions of the state of the NZ environment 2004}

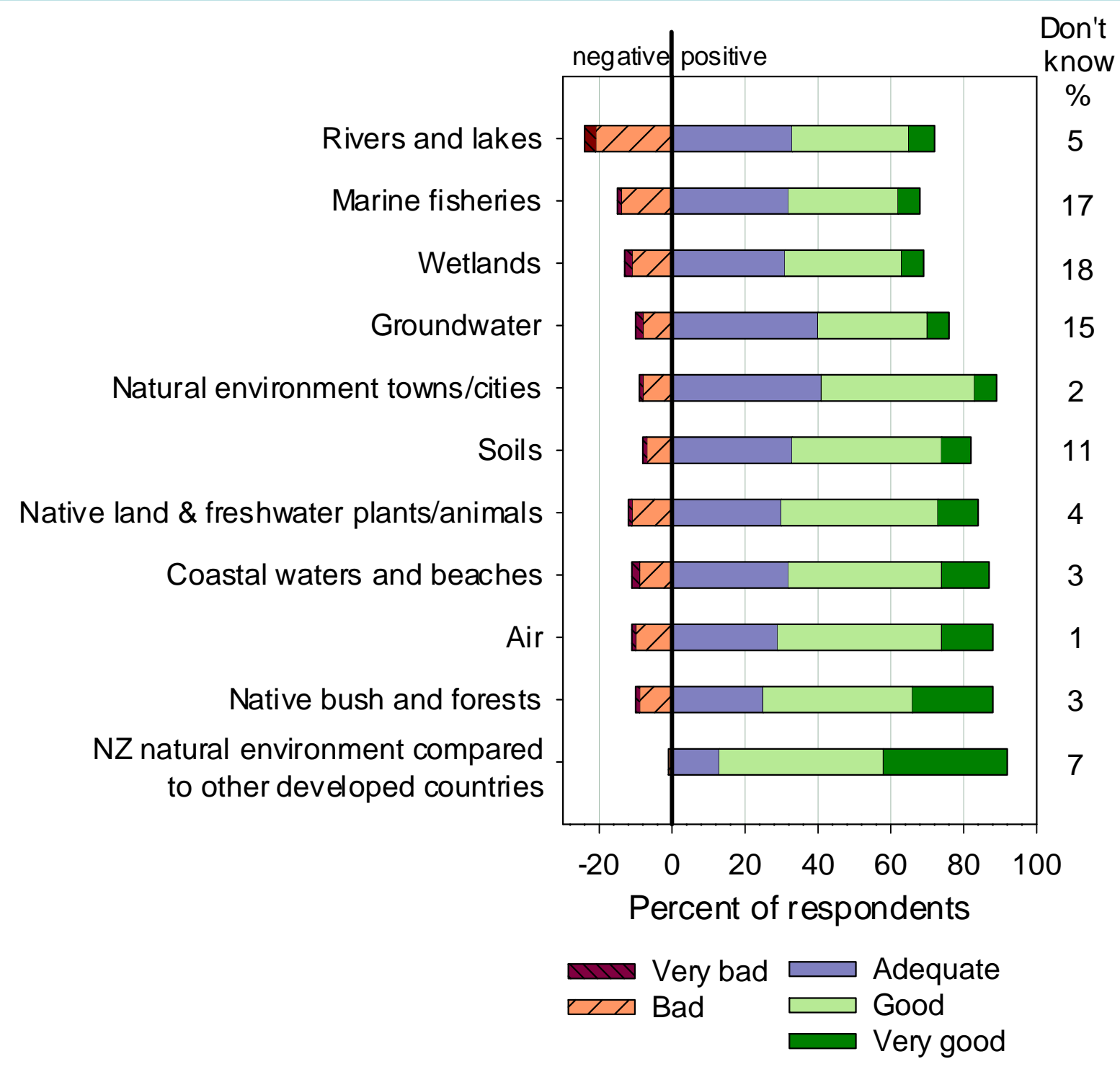




\section{State: changes in state of freshwater}

Quality of freshwater compared to 5 years previously

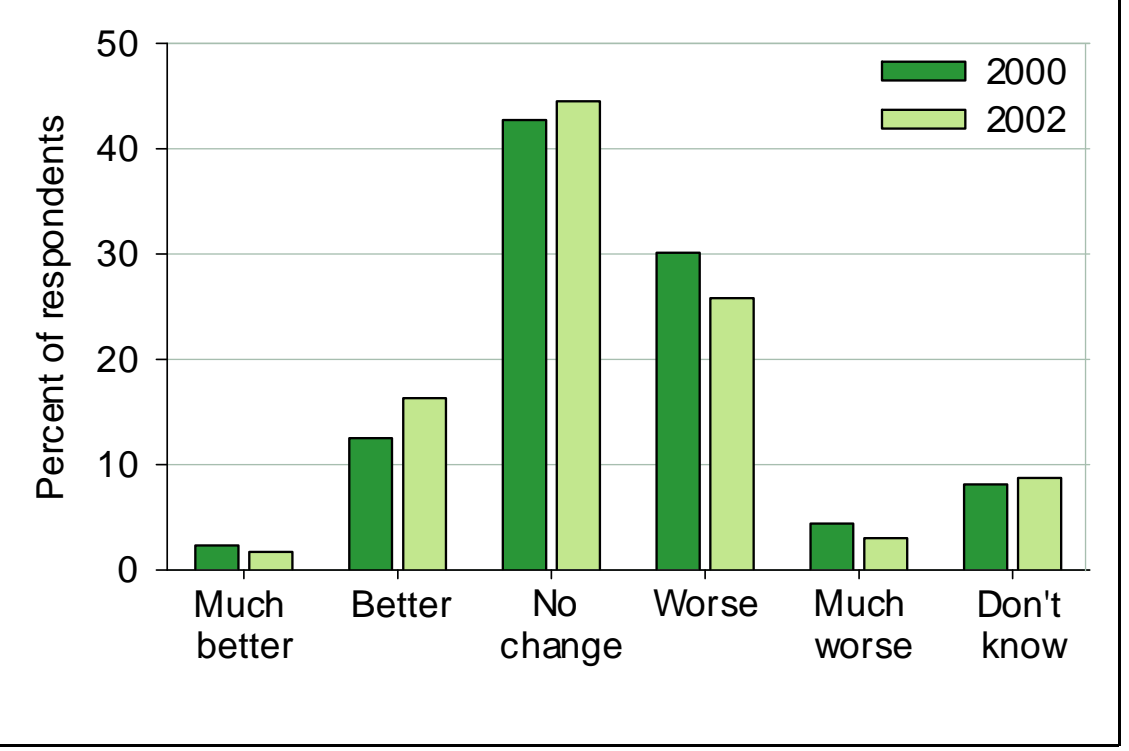

Water quality in 2004 compared to 5 years previously

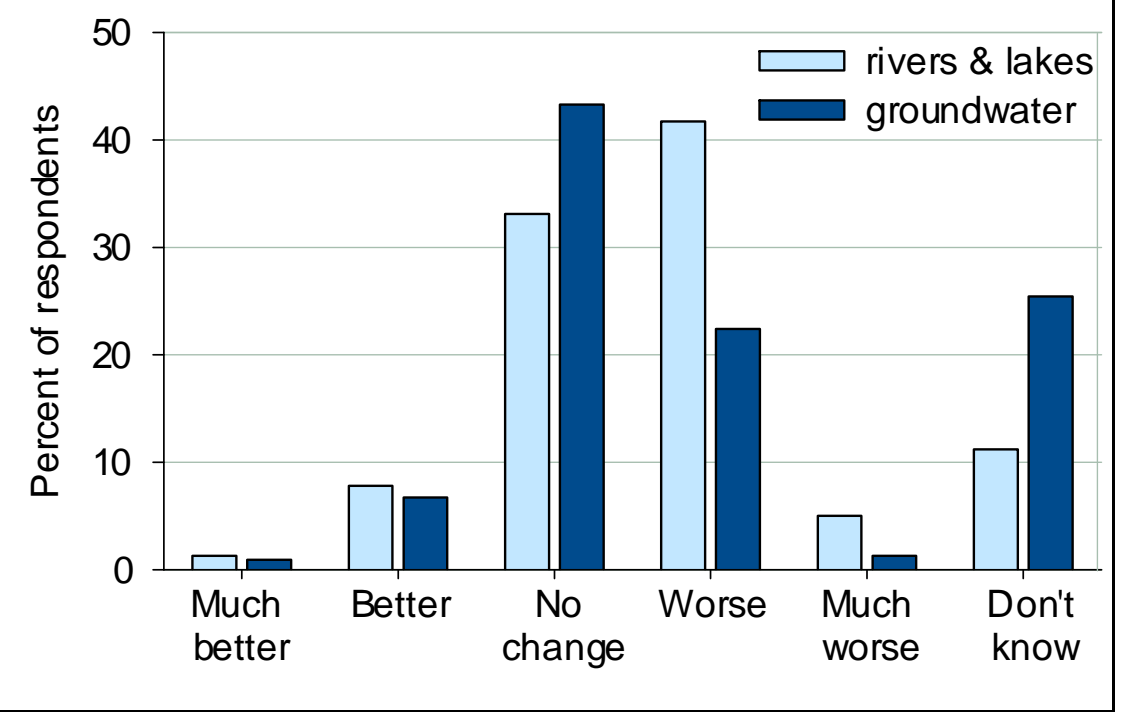




\section{State: Demographic differences - 2004}
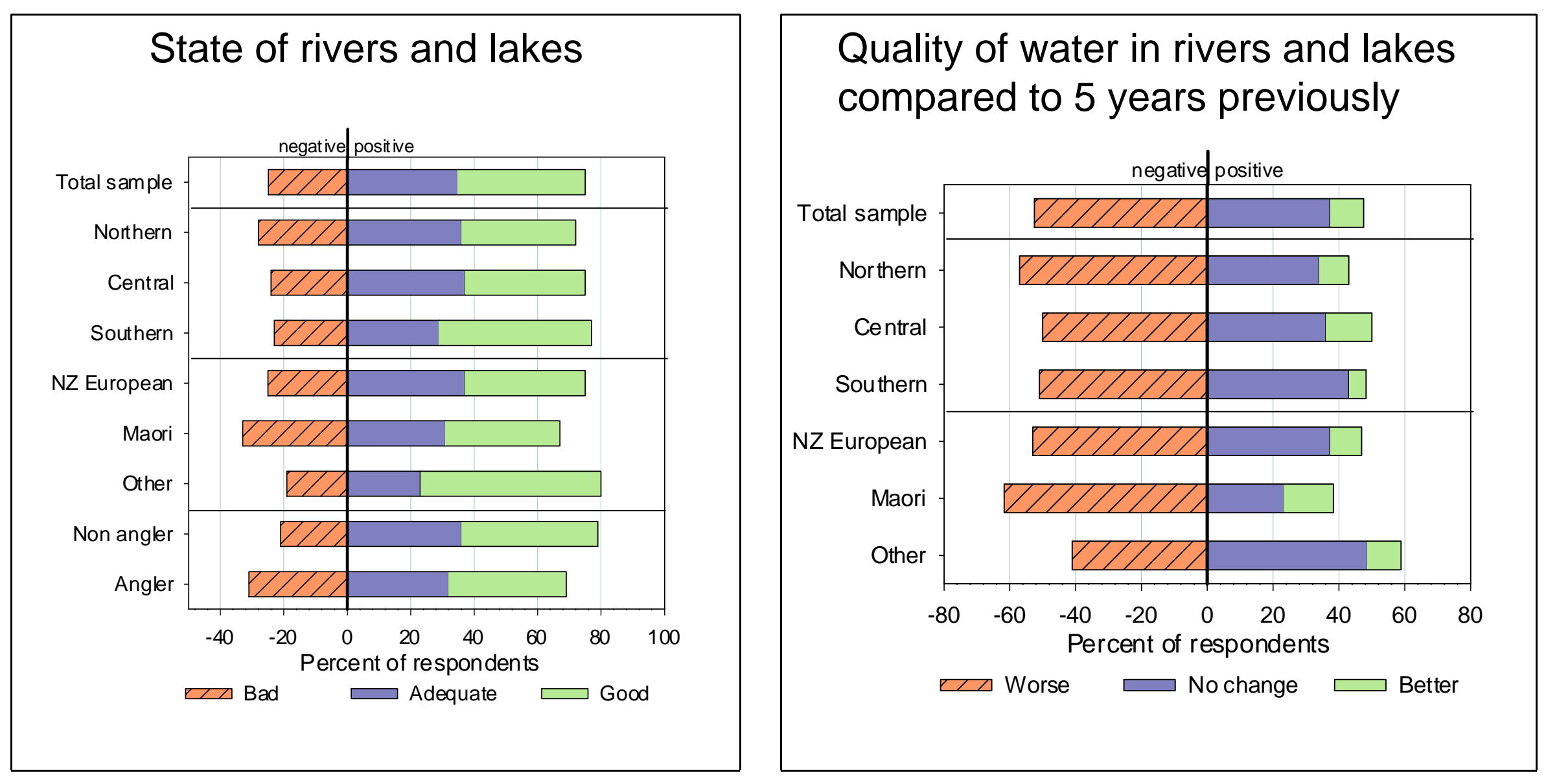


\section{Response: Management of freshwater 2004}
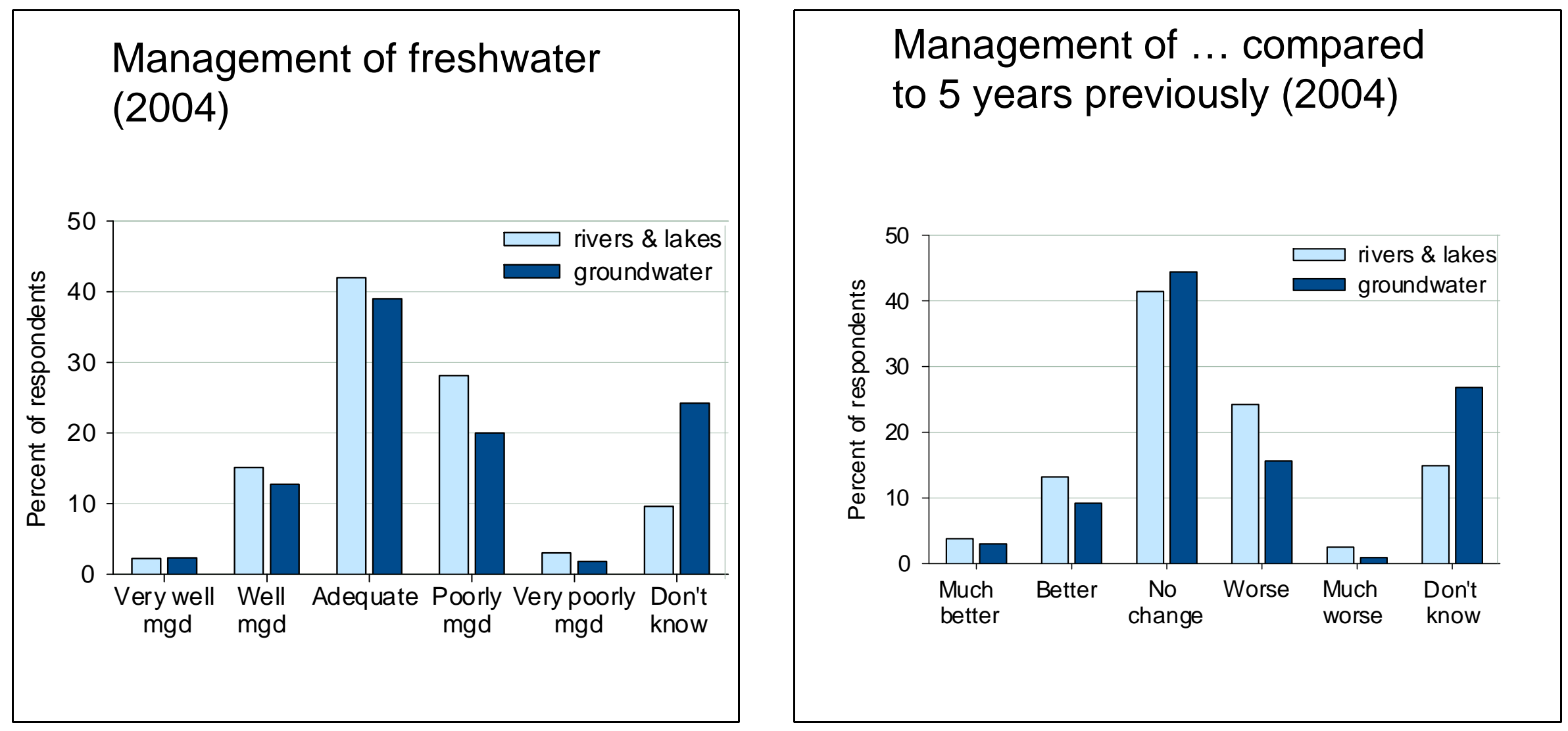


\section{Response: Quality of management activities (2000 - 2004)}

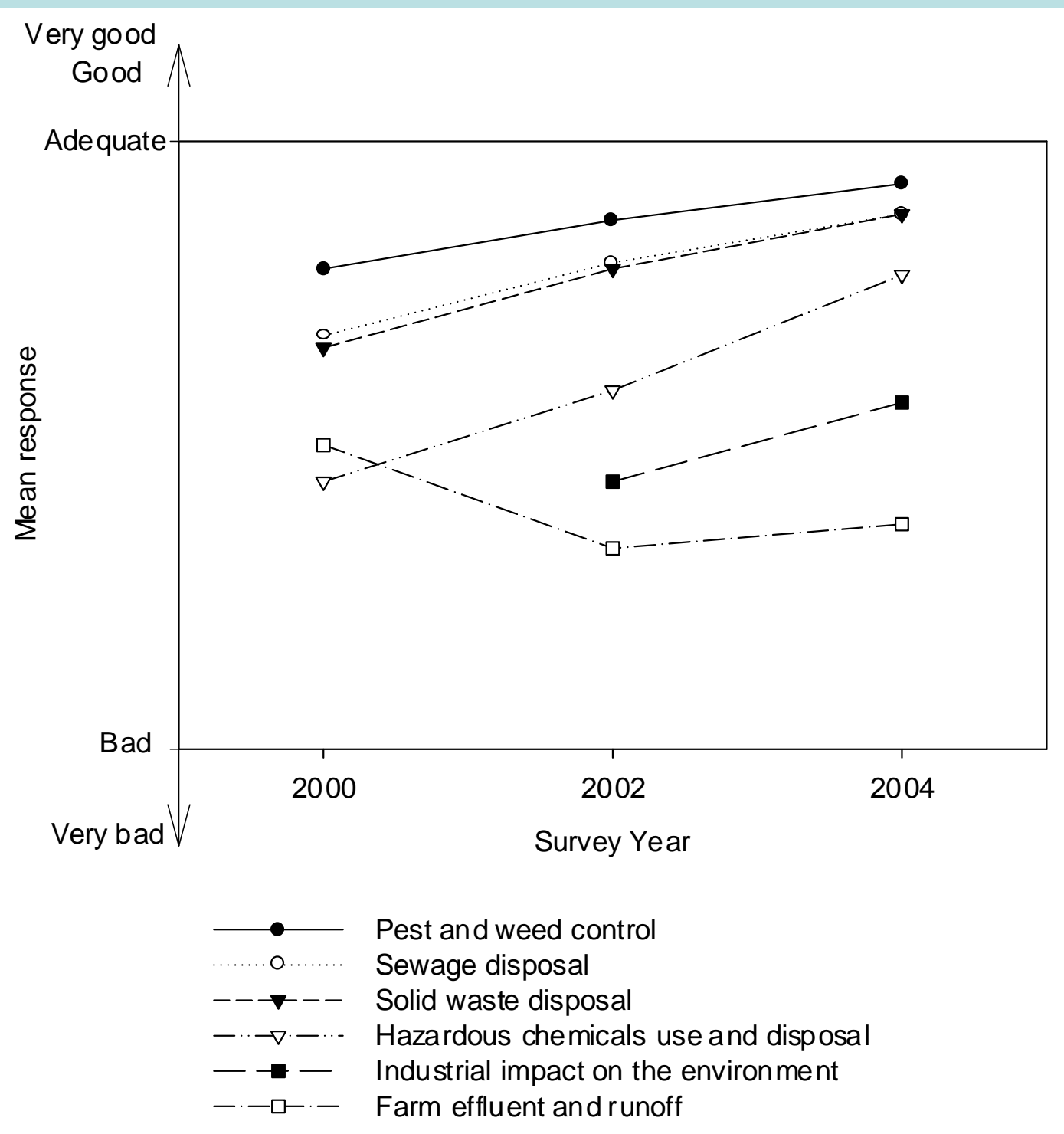




\section{Response: Demographic differences - 2004}
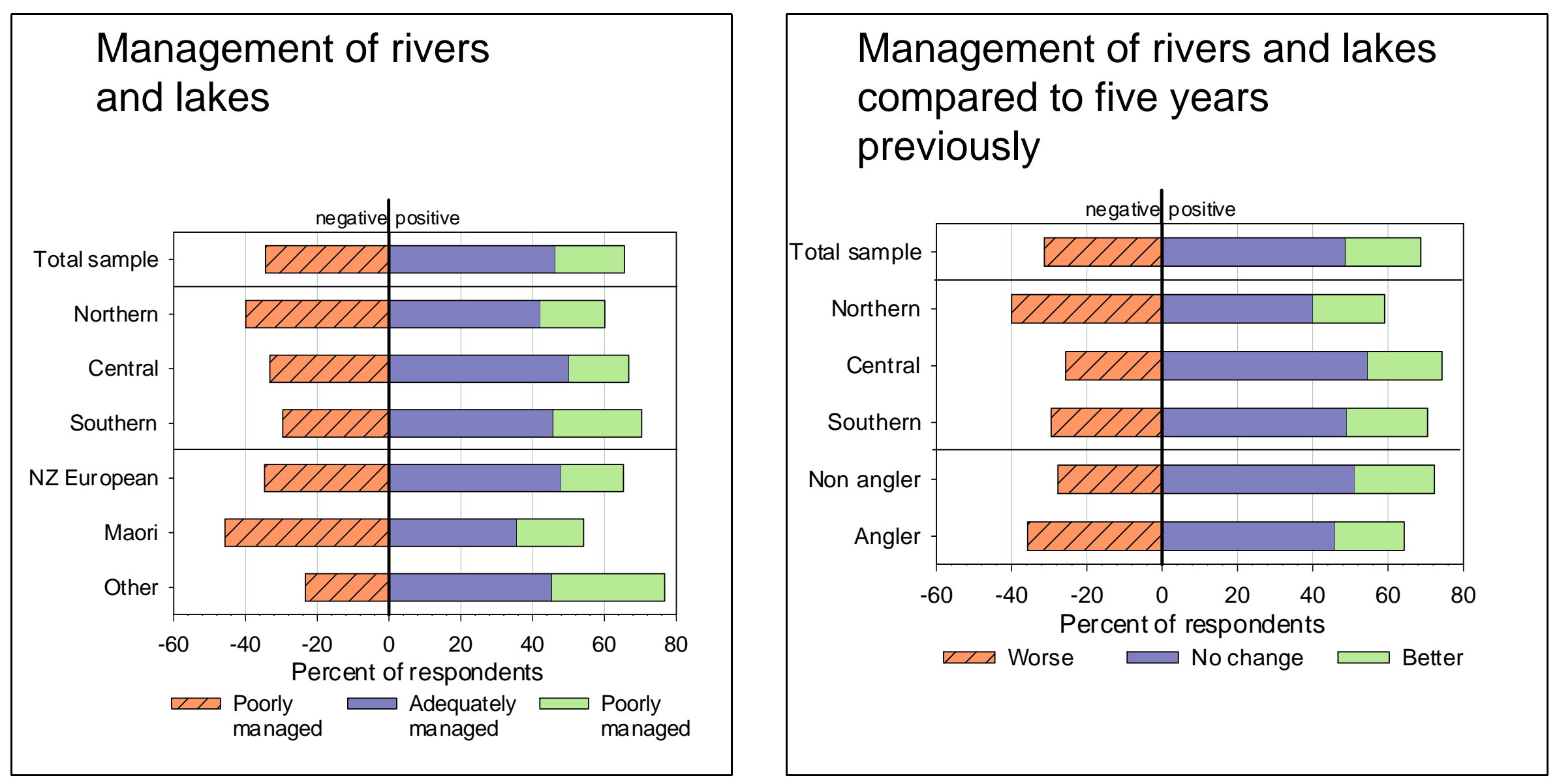


\section{Perceptions based on the}

context of specific water quality and quantity related issues -

\section{4 only}




\section{Opinion on freshwater statements (excluding 'don't}

\section{know' and 'neither agree nor disagree')}

A. More water should be taken from large rivers for irrigation, even if it has a negative impact on freshwater fisheries

B. Small lowland streams in my region have high quality water

C. Small lowland streams in my region are well managed

D. More water should be taken from small lowland streams for irrigation, even if it has a negative impact on freshwater fisheries

E. Small lowland streams in my region are in good condition

F. Water quality in small lowland streams in my region has not been damaged by dairy farming

G. More water should be taken from aquifers (underground) in my region

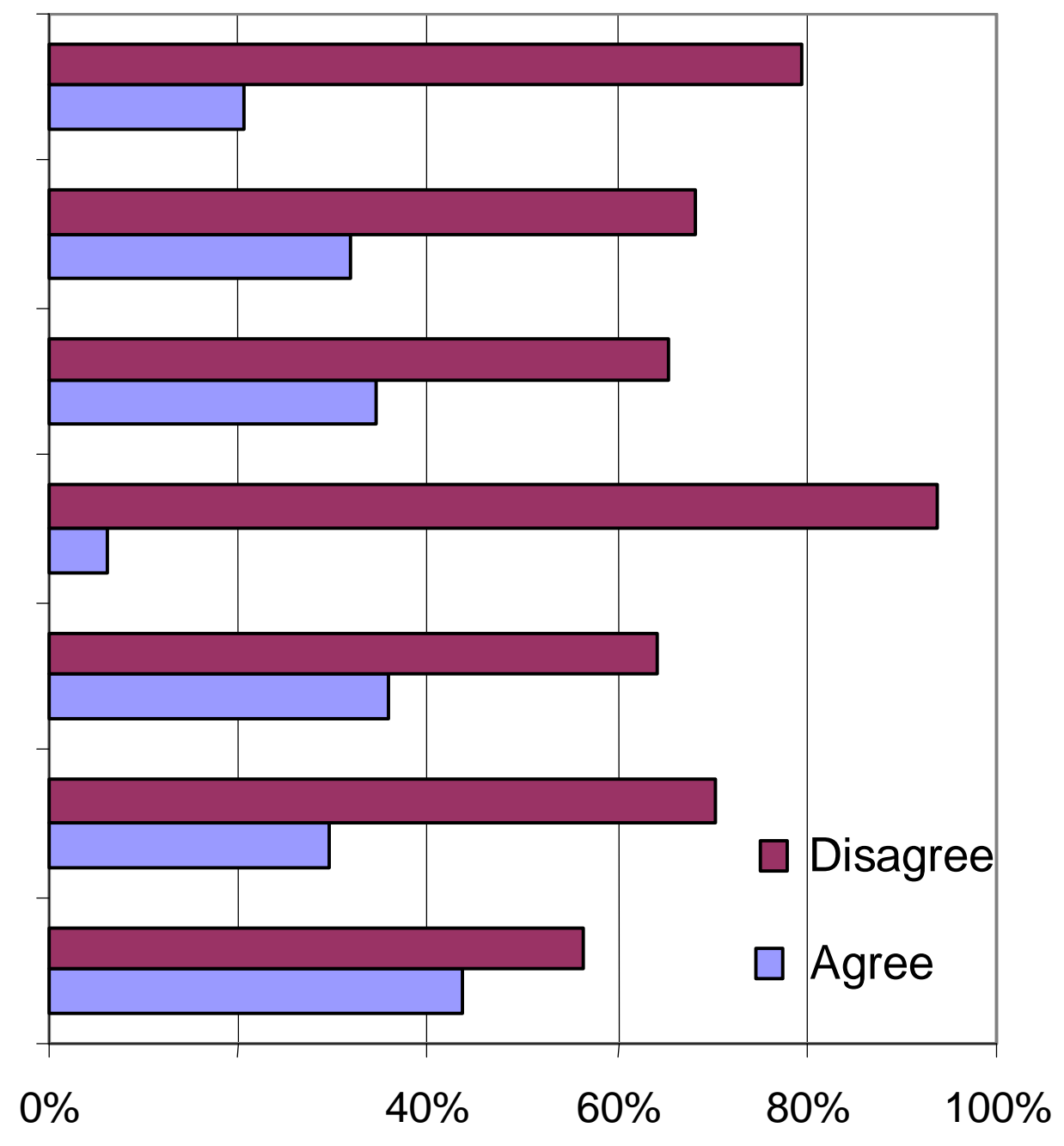




\section{Demographic differences - 2004}
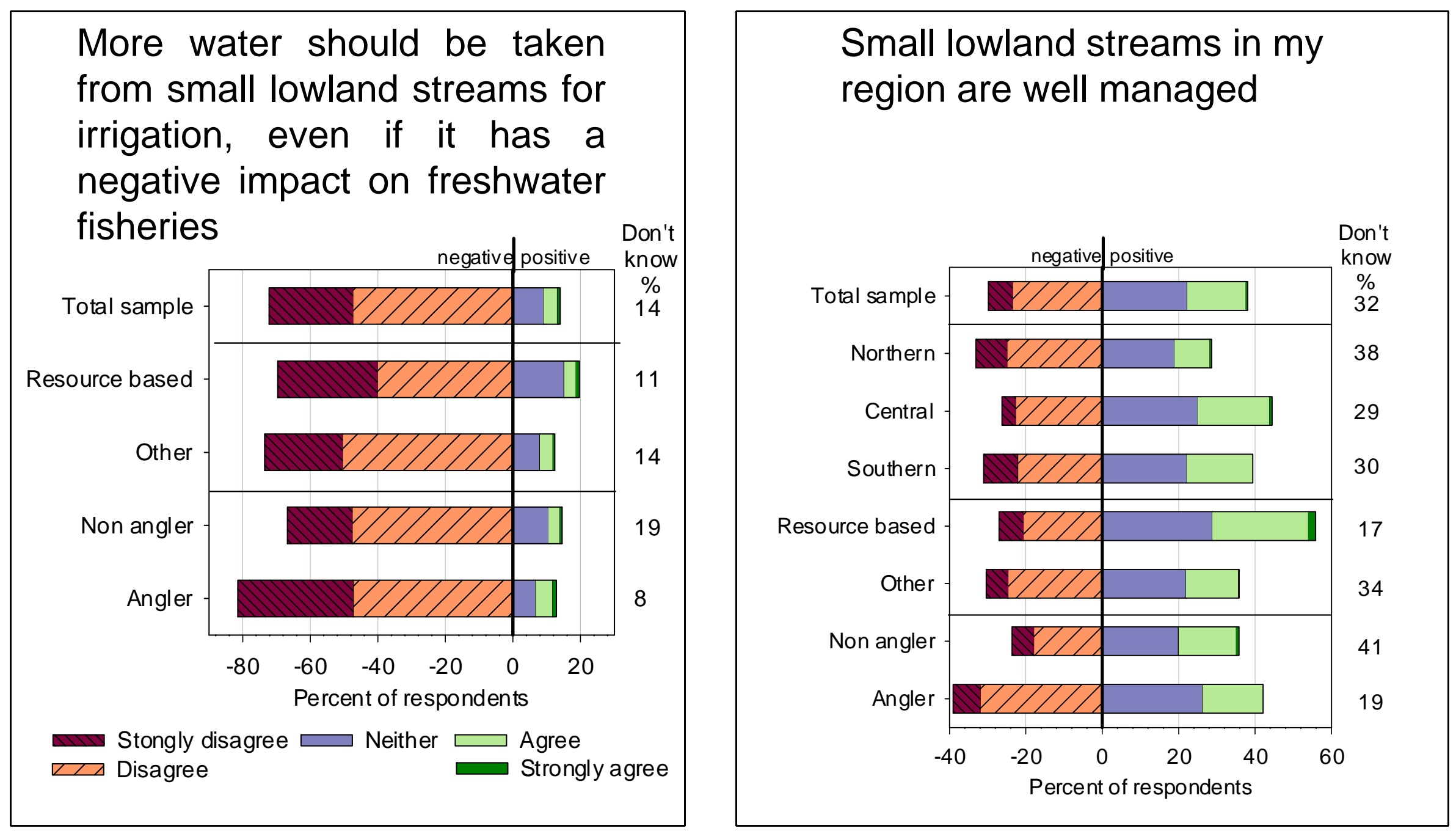


\section{Does Science' match perceptions}

1. The national situation:

- Based on available indicators and reporting NZ ranks $4^{\text {th }}$ best in a comparison of 146 nations for water quality and $13^{\text {th }}$ in terms of availability of freshwater (ESI report 2005);

- The perceptions survey also gave very high rankings for freshwater aspects.

- Science and perceptions match at a national indicator level.

2. Areas of specific concern:

- Agriculture, and dairy farming in particular, is placing excessive pressure on water quality (and quantity) in some areas (e.g., PCE 2004; Parkyn \& Wilcock 2004). Many low elevation streams are reported as having low overall water quality (Larned et al. 2004).

- New Zealanders share the same concerns as do scientists. These concerns are reflected by responses about impacts of farming, especially dairying, on small streams and rivers. In all instances there is a high level of concern in the perception survey responses.

- Science and perceptions match at a case-specific level. 


\section{Implications of the science - perceptions connection}

- Perceptions are a good barometer of reality and may provide an early indicator of problems that policy makers and others need to address.

- Because New Zealanders rate the state of almost all resources highly (a fact largely reinforced by Esty et al. 2005) these problem areas may only be identified where general questions are complemented by specific questions in key resource areas.

- It is also unclear as to what 'drives' these public perceptions, e.g., biophysical science or 'scare' campaigns. These issues are testable and could help drive future survey design. 


\section{Lessons from the demographic studies}

- Some of the differences could contribute to policy initiatives.

- The $38 \%$ of respondents defined as 'anglers' are clearly concerned about many freshwater issues - this is a considerable proportion of those aged over 18 and they might influence policy decisions.

- The concerns stated by Maori about water quality issues have direct Treaty and policy implications which ultimately could be reflected in politicisation of the issues.

- People employed in resource-based industries are at times less concerned about water-related matters than are other people. But perceptions findings match scientific findings and a signal needs to be sent to this sector that their views are at times incorrect.

- These differences raise significant questions about the direction, focus \& acceptability of water management policy. 


\section{Conclusions}

- The biennial survey findings show clearly, at a national level, perceptions are consistent with biophysical research findings, i.e., the state of New Zealand freshwater is good.

- At a more specific, issue-based level, perceptions match growing scientific concern about freshwater.

- Given that scientists report increasing problems and the public perceives there are problems, the only impediment is a lack of national and regional level willingness to respond.

- The Water Programme of Action is a step in the right direction. Our survey results provide government with support to make some strong and immediate commitments to improving water quality and protecting water resources as desired by the community.

- A challenge - how to match policy responses on freshwater and its management to some of the key demographic variations that exist within this (mostly) supportive community. 